(2) Open Access Full Text Article

REVIEW

\title{
Standing the test of time in Europe? Gefitinib in the treatment of non-small-cell lung cancer
}

\author{
This article was published in the following Dove Press journal: \\ Lung Cancer:Targets and Therapy \\ 12 May 2010 \\ Number of times this article has been viewed
}

\section{Caroline Wilson \\ Sarah J Danson}

Academic Unit of Clinical Oncology, University of Sheffield, Broomcross

Building, Weston Park Hospital, Sheffield Teaching Hospitals NHS

Foundation Trust, Sheffield, UK
Correspondence: Caroline Wilson Weston Park Hospital, Whitham Road, Sheffield, SIO 2EJ, UK

Tel +44 I I 42265235

Fax +44 I | 42265364

Email caroline.wilson@sth.nhs.uk
Abstract: Lung cancer is the most common cancer worldwide, with 1.3 million new cases diagnosed every year. Non-small-cell lung carcinoma (NSCLC) has previously had a very poor prognosis with few effective therapies; however, research has identified that it is associated with a high rate of expression of epidermal growth factor receptor (EGFR) tyrosine kinase. This has led to discoveries in drug manipulation of this receptor, to provide effective new therapies against NSCLC. Gefitinib is a small molecule kinase inhibitor which inhibits the cytoplasmic domain of the EGFR; the evidence behind its use and future role is presented in this review. Keywords: non-small-cell lung carcinoma, gefitinib, epidermal growth factor receptor, tyrosine kinase, cigarette smoking

\section{Introduction}

Lung cancer is the most common cancer worldwide, with 1.3 million new cases diagnosed every year. Lung cancer incidence rates vary throughout the world with the highest incidence in men in central/Eastern Europe and North America, and in women, in North America and Northern Europe. Lung cancer is uncommon in patients $<40$ years, with a sharp increase in incidence aged $75-84$ with $85 \%$ cases occurring in patients $>60$ years. ${ }^{1}$ It is more prevalent in males than females, however with a decreasing incidence of cigarette smoking in males compared to females the historical ratio of 6:1 male:female has now changed to 4:3. Due to the relatively low survival rates for lung cancer the prevalence is low compared to the incidence.

There are two main histological types of lung cancer; small-cell (20\%) and non-small-cell $(80 \%)$; the distinction is important in tailoring treatment and predicting the natural history of the disease. The 'non-small-cell' group comprises several different histologies, the most common being squamous cell carcinoma, adenocarcinoma and large cell carcinoma (35\%,27\%, and 10\%), the remainder being of nonspecific type. In the US the most common type is adenocarcinoma, although in Europe the most common is squamous cell carcinoma. Adenocarcinoma is the most common in non-smokers and its increasing incidence has been linked to low tar cigarettes. ${ }^{2}$

Risk factors for lung cancer include cigarette smoking, poor diet and industrial carcinogens, ie, uranium, arsenic, beryllium, coal products, mustard gas and asbestos exposure. Cigarette smoking directly accounts for $87 \%$ of lung cancer deaths. ${ }^{3}$ A personal or family history increases risk and DNA changes on chromosome 6 leads to an increased risk of developing lung cancer irrespective of smoking status. ${ }^{3}$ 
Patients often present with advanced disease, and even those who have early stage disease and receive 'radical', potentially curative treatment, often relapse with metastatic disease. ${ }^{4}$ In advanced disease a cure is not possible and palliation of symptoms and the quality of life (QOL) of patients become paramount. Chemotherapy has been proven to improve survival when used in the neoadjuvant and adjuvant settings ${ }^{4}$ with early stage disease; however, its use in advanced disease still leads to disappointing results which therefore makes research into new agents vital. ${ }^{5,6}$

NSCLC is associated with a high rate of expression of epidermal growth factor receptor (EGFR) tyrosine kinase, and EGFR over expression has been associated with a poor prognosis and resistance to standard therapies. ${ }^{7}$ Veale and colleagues demonstrated that survival $>5$ years, following surgical resection of NSCLC, was limited to those patients with a lower expression of EGFR. This suggests that EGFR quantification may give independent prognostic information in NSCLC, and help to select patients for adjuvant therapy after surgery. ${ }^{8}$ Targeting EGFR has been an area of great research interest as inhibition can block biological pathways involved in tumorigenesis. Several agents that block EGFR have been researched as potential therapies in NSCLC including gefitinib $\left(\right.$ Iressa $\left.^{\circledR}\right)$, erlotinib $\left(\right.$ Tarceva $\left.^{\circledR}\right)$, cetuximab $\left(\right.$ Erbitux $\left.^{\circledR}\right)$ and vandetanib $\left(\right.$ Zactima $\left.^{\circledR}\right)$.

\section{Pharmacology and pharmacokinetics}

The EGFR receptor is a transmembrane glycoprotein with an extracellular ligand binding domain which is blocked by larger monoclonal antibodies, and an intracellular tyrosine kinase signaling domain which is blocked by small molecule kinase inhibitors. Following activation of EGFR, the glycoprotein undergoes a transition from an inactive monomeric form to an active homodimer. Dimerization stimulates the intrinsic intracellular protein-tyrosine kinase activity which involves activation of downstream signaling pathways including RAS-RAF-MAPK and PI3-K. ${ }^{9}$ These downstream signaling proteins provoke DNA synthesis, resistance to apoptosis, angiogenesis and thus cell proliferation.

In malignant cells the activity of the EGFR may be dysregulated by several mechanisms including EGFR gene mutation, increased gene copy number and EGFR protein overexpression. ${ }^{10}$ Kinase domain mutations are referred to as 'activating mutations' as activation leads to ligand-independent, constant stimulation of the intracellular pathways which ultimately promote proliferation, angiogenesis, survival and metastasis. The activating mutations of the EGFR gene are found on exon 18-21. They fall into 3 main classes: class I are in-frame deletions in exon 19, accounting for $44 \%$ of all EGFR mutations; class II are nucleotide substitutions predominantly on exon 21 (L858R) and accounts for $41 \%$ of all EGFR mutations; and class III are duplications/insertions in exon 20 and account for $5 \%$ of EGFR mutations. There may be differing sensitivities to tyrosine kinase inhibitors (TKI) depending on the type of mutation present, ie, a greater response is seen with exon 19 mutations compared to exon 21 mutations. ${ }^{11-14}$

Although EGFR kinase mutations lead to an increased sensitivity to EGFR inhibitors, not all mutations are 'activating', and some can be associated with resistance to EGFR inhibitors, such as insertion mutations in exon $20 .{ }^{15}$ Another recognized mutation associated with resistance to EGFR inhibitors is the presence of KRAS gene mutation. This mutation occurs in $20 \%-30 \%$ of NSCLCs, mainly in adenocarcinomas (30\%) and smokers (18\%) and is reported to be associated with a poor response to EGFR TKIs, even when the two mutations are present in the same tumor cells. ${ }^{16}$

The mechanism of resistance may be due to one or more of several reasons: ${ }^{17}$

- Activation of EGFR-independent tumor - induced angiogenesis. In tumor models, cancer cells with increased EGFR and vascular endothelial growth factor (VEGF) expression are resistant to EGFR antagonists due to the alternative enhanced VEGF pathway providing growth promoters needed by the tumor cells. ${ }^{17}$

- Independent activation of intracellular pathways downstream to the EGFR. Drug-induced selective pressure may lead to cancer cells finding alternative cell survival pathways after prolonged use of EGFR TKI ie, amplification of MET, a receptor tyrosine kinase, has been demonstrated in gefitinib/erlotinib resistant NSCLC specimens. ${ }^{18}$ MET can activate PI3k thus allowing activation of the downstream signaling pathway independent of EGFR activity.

- EGFR gene mutations. The point mutation T790M is found in $50 \%$ of patients who are resistant to EGFR TKI therapy ${ }^{19}$ and the mutation is believed to occur due to selective pressure during treatment. Maheswaran and colleagues detected the T790M in $64 \%$ of circulating tumor cells in patients who had had progression on a TKI and in 33\% of patients who had had a response to TKI; indicating this resistant mutation is common in patients who clinically progress on treatment. ${ }^{20}$ Zhou and colleagues demonstrated that the T790 mutation restores the affinity of adenosine triphosphate (ATP) thus rendering the EGFR kinase domain similar to that of the wild type (WT). Concurrent inhibition of T790 mutation has been dose limited due to 
toxicity secondary to concurrent blockade of the EGFR WT leading to skin rash and diarrhea. The use of EGFR inhibitors that selectively inhibit the T790 mutation, yet do not concurrently inhibit EGFR WT, may lead to EGFR inhibitors that are clinically more effective, and may lead to a longer time to progression due to a lack of resistance, whilst being better tolerated by patients. ${ }^{21}$

It appears that smoking may influence the pattern of EGFR mutations in NSCLC, not only with KRAS but other tumor cell characteristics. EGFR mutations in exon 19 and 21 are less frequent in female smokers; and in males, mutations in exon 18, 19 and 21 are less frequent in smokers compared to non-smokers. There is no difference between smokers and non-smokers in exon 20 mutations. ${ }^{22}$ The presence of EGFR mutations is inversely proportional to tobacco consumption. ${ }^{23,24}$ Mounawar and colleagues found that in current smokers, EGFR mutations appear less frequently when compared to non- or past smokers; with an increase in P53 and KRAS in current smokers compared to previous or never smokers; ${ }^{25}$ this has been confirmed in further studies. ${ }^{26,27}$ Clinically this suggests that patients who will respond to EGFR TKI can be predicted, as certain clinical features will reflect molecular mutations. Rosell and colleagues ${ }^{28}$ screened 2105 patients with NSCLC and found $16.6 \%$ to be EGFR positive, with the mutation being found most frequently in women $(69.7 \%)$, never smokers $(66.6 \%)$ and those with histologically confirmed adenocarcinomas (80.9\%). Common mutations were found to be deletions of exon 19 and L858R on exon 21. These two mutations are documented to be associated with the best clinical response to gefitinib ${ }^{29}$ with response rates found to be $\sim 75 \%$ in Asian populations ${ }^{30-32}$ and $\sim 50 \%$ in non-Asian patients. ${ }^{33}$ Whether the improved response in EGFR mutation positive patients correlates to an overall survival advantage will be discussed later.

The main EGFR inhibitors which have been studied in NSCLC include gefitinib, erlotinib, cetuximab and more recently the dual EGFR and VEGF inhibitor vandetanib. Here we focus on gefitinib, and also summarize data relating to the alternative EGFR inhibitors.

Gefitinib is an orally available small molecule kinase inhibitor which inhibits the cytoplasmic domain of the EGFR tyrosine kinase. Gefitinib is an anilinoquinazoline compound which inhibits the intracellular tyrosine kinase domain of EGFR; it also inhibits ATP-binding cassette transporter-mediated drug efflux, ${ }^{34}$ thus increasing intracellular concentrations further (shown in Figure 1). Gefitinib is orally administered, metabolized in the liver by cytochrome P450 enzymes and has a half-life of 48 hours. It is extensively distributed after absorption, $90 \%$ is bound to plasma proteins and it is excreted in urine and feces. It is used with caution in hepatic impairment as gefitinib is primarily excreted in the liver. CYP3A4 inhibitors may decrease metabolism leading to increased plasma concentrations, ie, clarithromycin, erythromycin, ketoconazole; whereas CYP3A4 inducers may reduce the efficacy of gefitinib by lowering plasma concentrations, ie, St John's wort, carbamazepine, phenytoin, H2 antagonists and proton pump inhibitors. Gefitinib also interacts with warfarin and can enhance the anticoagulant effect.

Cetuximab is an intravenous chimeric human-mouse monoclonal antibody that has a high affinity for the extracellular ligand binding domain of the EGFR causing: receptor internalization; inhibition of phosphorylation; and thus the blockage of downstream signaling pathways such as bax, caspase 3, 8 and 9. Cetuximab was investigated in pretreated NSCLCs in a phase II trial in addition to docetaxel $75 \mathrm{mg} / \mathrm{m}^{2}$ in patients who had progressed on prior platinum chemotherapy; a median survival time of 7.5 months was reported and a $28 \%$ response rate. ${ }^{35} \mathrm{~A}$ phase II trial was conducted with cetiximab as monotherapy in pretreated NSCLCs, with a median survival of 8.1 months and 1 year survival of $41 \% .{ }^{36}$ Cetuximab's use as a first line therapy was investigated in three phase II trials, in addition to platinum-containing chemotherapy, as first line treatment in EGFR mutation positive patients. No trial demonstrated a statistically significant benefit from addition of cetuximab to chemotherapy on overall response rate (ORR), median progression free survival (PFS) or median overall survival (OS) ${ }^{37-39}$ More recently, Pirker and colleagues compared cisplatin and vinorelbine with or without the addition of cetuximab in 1125 chemonaïve patients, with confirmed EGFR expression. A significant improvement in the median OS was demonstrated (11.3 months versus 10.1 months, $P=0.044)$. Therefore the use of cetuximab, first line, in conjunction with chemotherapy may have a future role in EGFR selected populations. ${ }^{40}$

Erlotinib is an orally active TKI, inhibiting the intracellular domain of the EGFR. In the BR.21 trial patients received erlotinib $150 \mathrm{mg}$ daily versus placebo, 731 patients were recruited; the majority were performance status (PS) $\leq 2$, and of the 488 patients treated with erlotinib, 38\% had complete or partial response to prior chemotherapy. The ORR was greater with erlotinib $(8.2 \%$ versus $<1 \%$ respectively, $P \leq 0.001)$ with the likelihood of response greater in women $(P=0.006)$, non-smokers $(P \leq 0.001)$, Asians $(P=0.02)$ and those with adenocarcinoma $(P \leq 0.001)$. Median OS and PFS was higher with erlotinib than placebo (6.7 months and 4.7 months $P \leq 0.001 ; 2.2$ months and 1.8 months $P \leq 0.001$ 


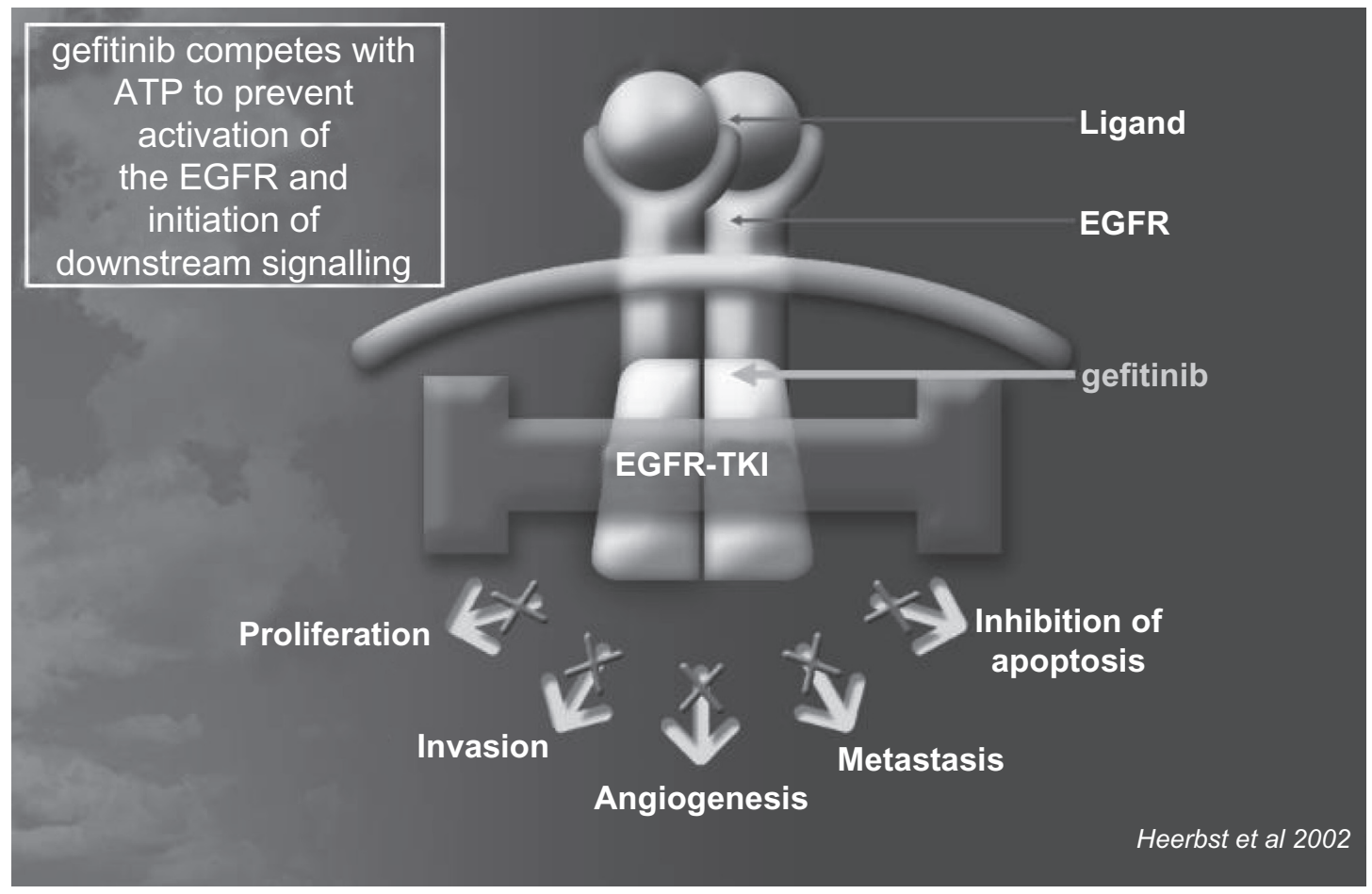

Figure I Mechanisms of EGFR inhibition by gefitinib. Reproduced with permission from Herbst RS. ZDI839: targeting the epidermal growth factor receptor in cancer therapy. Expert Opin Investig Drugs. 2202; 1 I:837-849. ${ }^{105}$ Copyright (C) 2002 Informa Healthcare.

respectively) ${ }^{41}$ Results of BR.21 have led to the worldwide use of erlotinib as a second line agent in the treatment of NSCLC. However, trials of erlotinib in combination with chemotherapy have not demonstrated consistent advantages to concurrent treatment, except in the subgroup of never smokers (22.5 versus 10.1 months for placebo). ${ }^{42,43}$

SATURN (Phase III Sequential Tarceva in Unresectable NSCLC study) was a randomized phase III trial which investigated the role of erlotinib as maintenance therapy following the non-progression after 4 cycles of first line platinum therapy. The primary end point of PFS was significantly prolonged with erlotinib versus placebo with a $41 \%$ increase $(P<0.0001)$, as was the disease control rate, indicating that erlotinib in first line maintenance is well tolerated and effective. Overall survival data have recently been presented and demonstrates an increase in survival of 11 months to 12 months with maintenance erlotinib versus placebo. The effect was the same regardless of whether the tumor was positive or negative for EGFR. ${ }^{44}$ These results may change the timing of the use of erlotinib; prior to this erlotinib has been used on disease progression after the failure of first line therapy, however, there may be a role for use of erlotinib earlier to prolong PFS. The data on OS in SATURN supports this when compared to BR.21 (12 months versus 6.7 months).

Vandetanib is an orally available TKI that inhibits both EGFR and VEGF and is currently being researched in
NSCLC in several large phase III trials: Zodiac, Zeal, Zest, Zephyr. ${ }^{45-49}$ Zodiac compared docetaxel with or without the addition of vandetanib at $100 \mathrm{mg}$ daily or $300 \mathrm{mg}$ daily in 1391 patients. A statistically significant increase in PFS was seen with vandetanib at either dose, compared to docetaxel alone (12 weeks versus 18.7 weeks and 17 weeks respectively).

Zeal compared pemetrexed with or without vandetanib in 543 patients and did not demonstrate a statistically significant difference in PFS between the two groups (11.9 weeks versus 17.6 weeks with vandetanib).

Zest compared erlotinib with vandetanib in 1240 patients and did not demonstrate any statistically significant improvement in the PFS when compared with erlotinib.

Zephyr, comparing vandetanib with best supportive care, continues to recruit. A recent phase II trial compared vandetanib with gefitinib in over 100 pre-treated NSCLC patients. Vandetanib produced a statistically significant lengthening of PFS over that of gefitinib (11.9 weeks versus 8.1 weeks $P=0.025) .{ }^{49}$ Thus to date vandetanib has shown no major advantage over currently used TKIs.

\section{Efficacy}

It is now 25 years since EGFR was identified as a potential anticancer target, ${ }^{50}$ and the data regarding the use of gefitinib is extensive. The worldwide use of gefitinib heightened 
around 2003, and to date, 315,000 patients have been treated with gefitinib (data from AstraZeneca database, 2009).

Between 2002 and 2003 phase I trials were conducted using gefitinib as monotherapy in a variety of solid tumor types $;{ }^{51}$ over 250 patients were enrolled in the phase 1 trials, 100 of whom had NSCLC, and all of whom had received prior anticancer therapy. Common side effects included grade 1 and 2 diarrhea and acneiform rash. A maximum tolerated dose was determined to be between $700 \mathrm{mg} /$ day and $1000 \mathrm{mg} /$ day; the dose limiting toxicity was found to be diarrhea. Tumor responses were observed with doses greater than $150 \mathrm{mg} /$ day in NSCLC, with associated symptomatic improvement. The results from phase 1 trials concluded that $250 \mathrm{mg}$ and $500 \mathrm{mg}$ were associated with tumor response and acceptable toxicity with minimal interruptions to dosing schedule. ${ }^{51-54}$

Phase II and III studies were then conducted using gefitinib in pre-treated advanced NSCLC and as first line therapy in advanced NSCLC.

\section{Gefitinib in pre-treated NSCLC Phase II trials}

Two randomized phase II trials, IDEAL I ${ }^{55}$ and $\mathrm{II}^{56}$ were conducted in 2003. IDEAL I was conducted in Europe, Australia, Japan and South Africa and IDEAL II in the USA. Recruitment to each trial was 210 and 221 patients respectively. They were both randomized, double blind parallel trials comparing the efficacy of $250 \mathrm{mg}$ versus $500 \mathrm{mg}$ daily gefitinib in pretreated patients. No difference was seen in response rate in either trial to the lower or higher gefitinib dose, either in symptomatic response or response based on RECIST (response evaluation criteria in solid tumors) criteria. The symptom improvement rate was around $40 \%$ in both trials and response, according to RECIST, ranged from $9 \%$ to $19 \%$ with $27 \%-36 \%$ having a stable disease. Following IDEAL I, a pre-planned subgroup analysis indicated that the response rate was higher in Japanese than non-Japanese patients $(27.5 \%$ versus $10.4 \%)$ and median survival with $250 \mathrm{mg}$ and $500 \mathrm{mg}$ was higher in Japanese patients than non-Japanese patients (13.8 and 11.2 months versus 7.6 and 8 months). Patients who were never smokers $(<100$ cigarettes in a lifetime), female and histologically adenocarcinomas also had an increased response.

Following the results of the IDEAL trials the Federal Drug Administration (FDA) approved gefitinib for use as a single agent after progression on a platinum agent or docetaxel. The lower dose of $250 \mathrm{mg}$ /day was chosen as there was no difference in efficacy but a lower incidence of toxicities.
In 2006 the phase II SIGN study (Second-line Indication of Gefitinib in NSCLC) compared gefitinib with docetaxel $\left(75 \mathrm{mg} / \mathrm{m}^{2}\right)$ in an open label randomized trial of 141 patients in Europe, the Middle East and South America. ${ }^{57}$ The non-superiority of gefitinib was demonstrated with similar results obtained with either therapy for: symptom improvement (36.8\% versus 26\%); QOL (33.8\% versus 26\%); overall survival ( 7.5 versus 7.1 months); and response rates (13.2 versus $13.7 \%$ ).

\section{Phase III trials}

In 2005 the Iressa Survival Evaluation in advanced Lung cancer (ISEL) was a double blind, placebo controlled trial set up to evaluate gefitinib versus best supportive care in pretreated patients. ${ }^{58} 1692$ patients were recruited from Europe, Asia, both Central and South America, Australia and Canada. The patients had either progressed through previous chemotherapy ( $45 \%$ ) or had not been able to tolerate a previous regimen. There was no significant difference in survival in the overall population between those patients who received gefitinib and those who received best supportive care (5.6 versus 5.1 months); however, a significantly higher objective response was observed for gefitinib versus placebo ( $8 \%$ versus $1.3 \%$ complete and partial response). A preplanned subgroup analysis showed a significant survival advantage for never smokers $(P=0.012)$ and Asian patients $(P=0.01)$, with a higher objective response with gefitinib in women, adenocarcinoma histology, Asian patients and never smokers.

In 2008 three phase III trials comparing gefitinib $250 \mathrm{mg} /$ day with docetaxel in pretreated patients were reported. The worldwide INTEREST trial (Iressa NSCLC Trial Evaluating Response and survival against Taxotere), ${ }^{59}$ the Japanese V-15-32 trial $^{60}$ and the Korean ISTANA trial ${ }^{61}$ (Iressa as Second Line Therapy in Advanced NSCLC-Asia). The results are shown in Table 1.

The primary objective of INTEREST was to demonstrate the non-inferiority of gefitinib compared to docetaxel, and this was achieved in terms of response rate and overall survival. A preplanned subgroup analysis was performed looking at the role of EGFR amplification, Asian patients, never smokers, adenocarcinoma and females. No superiority of gefitinib over docetaxel was demonstrated in these subgroups; however, whether these patients received gefitinib or docetaxel they had a longer overall survival (10.4 versus 12.2 months) compared to the median overall survival of around 8 months, suggesting a subgroup more responsive to treatments on relapse after failure of primary therapy. 
Table I Summary of INTEREST and V-I5-3259,60

\begin{tabular}{llllll}
\hline Trial & Patients $(\mathbf{n})$ & $\begin{array}{l}\text { Overall response rate } \\
\text { of gefitinib compared } \\
\text { to docetaxel }(\%)\end{array}$ & $\begin{array}{l}\text { Quality of life } \\
\text { improvement with } \\
\text { gefitinib compared } \\
\text { to docetaxel }\end{array}$ & $\begin{array}{l}\text { Median time to } \\
\text { progression on gefitinib } \\
\text { compared to docetaxel } \\
\text { (months) }\end{array}$ & $\begin{array}{l}\text { Median overall } \\
\text { survival with gefitinib } \\
\text { compared to } \\
\text { docetaxel (months) }\end{array}$ \\
\hline INTEREST & I466 & 9.1 vs 7.6 & $25.1 \%$ vs I4.7\% & 2.2 vs 2.7 & 7.6 vs 8.0 \\
& & $P=0.33$ & $P<0.000$ I & $P=0.47$ & $\mathrm{HR}=1.02$ \\
V-I5-32 & 490 & 22.5 vs I2.8 & $23.4 \%$ vs I3.9\% & 2.0 vs 2.0 & 11.5 vs I4 \\
& & $P=0.009$ & $P=0.023$ & $P=0.335$ & $P=0.33$ \\
\hline
\end{tabular}

Gefitinib was better tolerated than docetaxel with fewer common toxicity criteria (CTC) grade $\geq 3$ toxicities ( 9 versus $41 \%$ respectively).

V-15-32 involved Japanese patients and demonstrated an increased response rate although no improvement in overall survival rate was found when comparing gefitinib to docetaxel $\left(60 \mathrm{mg} / \mathrm{m}^{2}\right)$. Subsequent to the trial, in patients who had failed docetaxel and were female, never smokers, there was a high prescription rate of gefitinib which may have impacted on the survival figures in this group. The toxicity of gefitinib compared to docetaxel was similar to that seen in the INTEREST trial with a lower incidence of CTC grade $\geq 3$ toxicities (40.6 versus 81.6 with docetaxel).

ISTANA, a Korean trial, looked at progression free survival as a primary endpoint in 161 patients, and reported a longer time to progression with gefitinib than compared to docetaxel $(P=0.044)$ and a significantly improved response rate $(28 \%$ versus $7.6 \%, P=0.0007)$. CTC Grade $\geq 3$ toxicities occurred in $21.0 \%$ with gefitinib versus $27.6 \%$ with docetaxel, however there was no difference in QOL or symptom improvement noted between either therapy. ${ }^{59}$ These trials demonstrated the favorable toxicity profile of gefitinib compared to docetaxel, although there was no apparent increase in efficacy.

\section{Gefitinib as first line therapy}

Trials have looked at gefitinib as monotherapy or in combination with chemotherapy in chemonaïve advanced NSCLC.

\section{Phase II trials}

Monotherapy trials include that of Reck and colleagues ${ }^{62}$ which recruited 58 patients and randomized them to $250 \mathrm{mg} /$ day gefitinib; they found an overall response rate of $5 \%$, a median time to progression of 1.8 months and an overall survival of 7.3 months. A similar US study, recruiting 70 patients, reported a median time to progression of 3.7 months and an overall survival of 6.3 months.$^{63}$ Other similar US and European studies have found response rates and time to progression of $\sim 10 \%$ and 2 months respectively. ${ }^{64,65}$ Phase II monotherapy trials conducted in Asian populations reported higher response rates of $\sim 30 \%$ with a median time to progression varying between 3-14 months ${ }^{6,67}$ in an unselected population.

The INVITE study compared gefitinib with vinorelbine in elderly patients $>70$ years, with advanced NSCLC ${ }^{68}$ There was no statistical difference in efficacy with gefitinib compared to vinorelbine although gefitinib was better tolerated, with improvement in QOL of 24\% versus 11\% for gefitinib compared to vinorelbine, and CTC grade $\geq 3$ toxicities of $11.4 \%$ versus $65.6 \%$ respectively.

Gefitinib plus best supportive care was compared with placebo plus best supportive care in patients who were performance status 2 or 3 and not fit for chemotherapy. ${ }^{69}$ 201 patients were recruited and although there was a nonsignificant trend towards an improved median time to progression, OS; and overall response rate, the differences did not reach statistical significance. OS was 3.7 versus 2.8 months in gefitinib versus placebo. Quality of life improvement rates were similar with both gefitinib and placebo $(21.1 \%$ versus $20 \%$ ), and symptom improvement rates reflected a similar trend $(32.9 \%$ versus $30.8 \%)$.

\section{Phase III trials}

In 2004 two large randomized placebo controlled trials were undertaken in the US and worldwide (see Table 2). INTACT 1 recruited 1093 patients from America, Europe, South Africa and Asia. ${ }^{70}$ Gemcitabine + cisplatin was compared with and without the addition of gefitinib at $250 \mathrm{mg} /$ day and $500 \mathrm{mg} /$ day and daily gefitinib or placebo was continued until progression. No difference was demonstrated between placebo, gefitinib $250 \mathrm{mg} /$ day or gefitinib $500 \mathrm{mg} /$ day, with median survival times of 10.9, 9.9 and 9.9 months respectively. The median time to progression was 6.0, 5.8, 5.5 months respectively and response rates were similar at $47.2 \%, 51.3 \%$ and $50.3 \%$ respectively. No increase in toxicities were observed with gefitinib. INTACT 2 recruited 1037 patients, with the majority from the US. ${ }^{71}$ Paclitaxel and carboplatin were compared with or without the addition of gefitinib at $250 \mathrm{mg} /$ day and $500 \mathrm{mg} /$ day. There was no differ- 
Table 2 Summary of phase III trials using gefitinib first line ${ }^{67-69}$

\begin{tabular}{|c|c|c|c|c|c|c|}
\hline Trial & Question & Patients (n) & $\begin{array}{l}\text { Overall } \\
\text { response } \\
\text { CR + PR (\%) }\end{array}$ & $\begin{array}{l}\text { Progression } \\
\text { free survival } \\
\text { (months) }\end{array}$ & $\begin{array}{l}\text { Overall } \\
\text { survival } \\
\text { (months) }\end{array}$ & $\begin{array}{l}\text { Quality of life } \\
\text { improvement } \\
\text { (\%) }\end{array}$ \\
\hline \multirow[t]{4}{*}{ INTACT I } & gemcitabine + cisplatin & 1093 & 47.2 & 6.0 & 10.9 & Not formally \\
\hline & vs gemcitabine + cisplatin & & & & & assessed \\
\hline & + gefitinib $250 \mathrm{mg} / 500 \mathrm{mg}$ & & $51.2 / 50.3$ & $5.8 / 5.5$ & $9.9 / 9.9$ & \\
\hline & & & $P=$ not significant & $P=0.763$ & $P=0.456$ & \\
\hline \multirow[t]{4}{*}{ INTACT 2} & paclitaxel + carboplatin & 1037 & 28.7 & 5.0 & 9.9 & Not formally \\
\hline & vs paclitaxel + carboplatin & & & & & assessed \\
\hline & + gefitinib $250 \mathrm{mg} / 500 \mathrm{mg}$ & & $30.4 / 30$ & $5.3 / 4.6$ & $9.8 / 8.7$ & \\
\hline & & & $P=$ not significant & $P=0.056$ & $P=0.639$ & \\
\hline \multirow[t]{3}{*}{ IPASS } & paclitaxel + carboplatin vs & 1217 & 32.2 & 6.7 & 17.3 & 40.8 \\
\hline & gefitinib & & 43 & 24.9 & 18.6 & 48 \\
\hline & & & $P=0.001$ & $P<0.0001$ & $P=0.91$ & $P=0.01$ \\
\hline
\end{tabular}

Abbreviations: $C R$, complete response; $P R$, partial response.

ence in the median OS with placebo versus gefitinib $250 \mathrm{mg}$ /day versus gefitinib $500 \mathrm{mg}$ /day $(9.9,9.8,8.7$ months respectively). No difference was demonstrated in response rate or median time to progression. The expected toxicities were observed in the gefitinib arm with an increase in diarrhea and skin rash.

In 2009 the IPASS study (Iressa Pan Asian Study), an East Asian trial, reported on gefitinib versus carboplatin and paclitaxel. ${ }^{72}$ East Asian patients with advanced adenocarcinoma who were nonsmokers $(<100$ cigarettes in their lifetime) or former light smokers $(<10$ pack years and $>15$ years since cessation of smoking) were recruited in an open label study. The 12 month PFS was $24.9 \%$ with gefitinib compared with $6.7 \%$ with carboplatin-paclitaxel $(P<0.0001)$, and the QOL improvement was significantly higher with gefitinib versus carboplatin-paclitaxel ( $48 \%$ versus $40.8 \%, P=0.01$ ). The median overall survival however was similar between the two groups (18.6 months with gefitinib versus 17.3 months with carboplatin-paclitaxel, $P=0.91)$. Toxicities CTC grade $\geq 3$ with gefitinib included rash or acne (3.1\%) and diarrhea (3.3\%). Toxicities with carboplatin-paclitaxel included neurotoxic effects (5\%) and neutropenia (67\%). EGFR status was known in $56.1 \%$ (683 patients) and, of these, 437 patients could be evaluated. In the 261 patients who were EGFR mutation positive, their PFS was significantly longer with gefitinib than carboplatin-paclitaxel $(P<0.001)$ whereas in the mutation negative patients the PFS was greater with carboplatin-paclitaxel $(P<0.001)$, indicating that treatment should be tailored to EGFR status to ensure the best response to the most appropriate anticancer therapy.

\section{Gefitinib as maintenance therapy}

Mencoboni and colleagues evaluated 30 European patients treated with maintenance gefitinib after completion of six cycles of first line platinum containing chemotherapy; they demonstrated that gefitinib may be useful as a maintenance therapy in patients with adenocarcinoma. ${ }^{73}$ Patients with a histological diagnosis of adenocarcinoma were compared to those with nonadenocarcinoma histology. The overall median time to progression and median OS was 5 months and 8 months respectively. Patients who were confirmed adenocarcinoma had a time to progression and overall survival of 10 months and 15 months respectively. Patients with non-adenocarcinoma had a time to progression and OS of 3.2 months and 5.9 months respectively, indicating clinical selection of patients may identify those more likely to respond to gefitinib.

Wang and colleagues compared gefitinib maintenance, after induction therapy, with gefitinib treatment at subsequent relapses in an East Asian population. ${ }^{74} 173$ patients were randomized and the median time to progression and overall survival following maintenance versus treatment at relapse were 16.5 and 25 months compared with 9.2 and 12.5 months respectively ( $P=0.0004$ and $P=0.0001$ respectively) indicating gefitinib may be an appropriate maintenance therapy after induction chemotherapy.

The West Japan Thoracic Oncology Group (WJTOG) compared gefitinib maintenance with chemotherapy. Patients were randomized to 6 cycles of platinum containing chemotherapy (carboplatin-paclitaxel, cisplatinirinotecan, cisplatin-vinorelbine, cisplatin-docetaxel or cisplatin-gemcitabine) or 3 cycles of either chemotherapy regimen followed by gefitinib $250 \mathrm{mg}$ /day until progression. The median time to progression was significantly longer in those taking gefitinib when compared to chemotherapy, however, there was no difference in OS. ${ }^{75}$

Kelly and colleagues assessed the use of gefitinib after concurrent chemo-radiotherapy and docetaxel in inoperable 
stage III NSCLC (SWOG 0023). ${ }^{76}$ Patients with performance status $0-1$ were treated with cisplatin-etoposide with concurrent radiotherapy for 2 cycles, then consolidated with 3 cycles of docetaxel. Those patients who did not progress were randomized to gefitinib or placebo until progression. 243 patients were randomized, and an interim analysis demonstrated no difference in the median time to progression or OS, and therefore the study closed early. Median survival time was 23 months for gefitinib and 35 months for placebo $(P=0.013)$. Gefitinib therefore resulted in inferior survival compared with placebo, when delivered as maintenance therapy in this trial. The reasons for this remain unclear.

\section{Gefitinib in combination with other targeted therapies}

Multilevel cross stimulation occurs between the targeted agents, and as discussed earlier this has been suggested as a cause of EGFR resistance. Several phase I trials have combined gefitinib with another targeted agent.

Adjei and colleagues ${ }^{77}$ performed a phase I trial of gefitinib, $250 \mathrm{mg}$ daily in combination with sorafenib $400 \mathrm{mg}$ twice daily. Sorafenib is a multi-TKI which inhibits VEGF, PDGF, KIT, REF and RAF signaling pathways and thus is involved in the downstream signaling from a number of cell surface receptors including EGFR. 31 patients with pretreated NSCLC and PS $\leq 2$ were recruited; gefitinib had no effect on the pharmacokinetics of sorafenib but gefitinib $\mathrm{C}_{\max }$ and the area under the curve were reduced by concomitant sorafenib. 1 patient experienced partial response and 20 patients $(65 \%)$ experienced stable disease. PFS in the study population was 19 weeks.

A further phase I trial evaluated gefitinib in combination with AZD2171, a VEGFR-2 inhibitor. ${ }^{78}$ Adverse events predictably included diarrhea, rash and hypertension. A maximum tolerated dose (MTD) was identified as $30 \mathrm{mg}$ of AZD2171 in combination with $250 \mathrm{mg}$ /day gefitinib.

Resistance to EGFR inhibitors is linked to dysregulation of downstream apoptotic pathways ie, PI3K/Akt/PTEN axis. The mammalian target of rapamycin (mTOR) is a serine threonine kinase that has its effect downstream of Akt in regulating cell growth and cell cycle progression at the G1/S phase. The orally available mTOR inhibitor, RAD001 (everolimus) was evaluated in combination with gefitinib in a phase I trial. ${ }^{79}$ Pharmacokinetic data suggested no interaction between the two agents. The phase II data demonstrated the combination of RAD001 and gefitinib produces a $17 \%$ partial response rate in smokers with NSCLC. Toxicities CTC grade $\geq 2$ included diarrhea in $13 \%$ and pustular rash in $25 \%{ }^{80}$ Therefore combination therapies have so far not proved more effective than single agent TKI.

\section{How does gefitinib compare to erlotinib?}

Both phase I and phase II trials with erlotinib revealed a MTD of $150 \mathrm{mg}$ daily and a similar efficacy to gefitinib with an ORR of $12.3 \%$ and median PFS of 8.4 months. ${ }^{81}$

Phase III trials of erlotinib were undertaken; BR.21 compared erlotinib to $\mathrm{BSC}^{82}$ in pretreated patients and demonstrated an ORR of $8.9 \%(P<0.001)$ and a statistically significant increase in OS with erlotinib (6.7 versus $4.7, P \leq 0.001)$. Of note is the number of patients who had experienced complete response or partial response with a prior therapy before exposure to erlotinib was $38.1 \%$ in BR.21 compared to $18 \%$ with gefitinib in ISEL; whether this impacted on the difference seen in the results of these two trials has been debated, as there will have been a larger chemorefractory group in ISEL.

The TALENT trial compared the addition of erlotinib to cisplatin/gemcitabine combination and the TRIBUTE trial; conducted in the US, compared the addition of erlotinib to carboplatin/docetaxel. TALENT demonstrated an ORR with erlotinib of $31.5 \%$ and without $29.9 \%$ ( $P=$ not significant), PFS was 25.4 weeks and 23.9 weeks respectively $(P=0.045)$ and there was no statistical difference in median OS (43 weeks versus 44 weeks respectively, $P=0.49$ ). A preplanned subgroup analysis on non-smokers, EGFR mutational analysis and the incidence of rash was performed. In non-smokers there was a statistically significant difference in PFS with erlotinib (7.9 months versus 5.4 months, $P=0.02$ ); EGFR expression did not correlate to the response rate or survival; grade 3 rash was associated with a significant PFS compared to no rash (387 days versus 227 days, $P=0.0001) .{ }^{43}$ TRIBUTE demonstrated a similar ORR with or without erlotinib $(21.5 \%$ versus $19.3 \%$, $P=0.36)$ and a median OS of 10.6 months and 10.5 months respectively $(P=0.95)$. A preplanned subgroup analysis which included sex, race, EGFR expression and never smokers, revealed significance only in the never smokers with PFS and OS with erlotinib of 6.0 and 22.5 months and 4.3 and 10.1 months without $(P=0.002$ and $P=0.01$ respectively). ${ }^{42}$

These results are comparable to those of INTACT 1 and INTACT 2 where gefitinib was added to chemotherapy. The patient population was unselected in these trials and no advantage to addition of TKI to chemotherapy was seen in the overall trial population. The subgroup analysis of the INTACT 
trials demonstrated no improved survival apart from a trend towards improved survival in adenocarcinomas in patients who received $\geq 90$ days chemotherapy in INTACT 2 .

\section{Dosing strategy}

The MTD of gefitinib was $700 \mathrm{mg}$ /day in the phase I studies. Tumor responses were observed with doses greater than $150 \mathrm{mg} /$ day in NSCLC, and a symptomatic improvement was also demonstrated. The results from the IDEAL trials concluded that $250 \mathrm{mg}$ and $500 \mathrm{mg}$ were associated with tumor response and acceptable toxicity with minimal interruptions to dosing schedule $\mathrm{e}^{55,56}$ and the lower dose was chosen as its efficacy appeared equal and provided adequate gefitinib exposure as demonstrated in skin biopsies. ${ }^{52}$ It is given as a daily tablet with $60 \%$ oral absorption and time to peak plasma concentration is 3-7 hours. ${ }^{34}$ It has a large volume of distribution (1400-1600 L) and therefore has a high uptake in tumor tissues at the lower dose of $250 \mathrm{mg} /$ day. ${ }^{83}$ Gefitinib is cleared primarily via CYP3A4 hepatic metabolism; however, in patients with moderate to severe hepatic dysfunction, due to liver metastasis, the metabolism of gefitinib $250 \mathrm{mg} /$ day was similar to groups with normal hepatic function suggesting that gefitinib is safe in metastatic liver disease.

Questions have been raised as to whether the chosen dose of gefitinib in the phase II and III trials was too low and therefore may account for the different results seen when compared to the trials of erlotinib. Erlotinib was investigated at its MTD compared to gefitinib where a dose $40 \%$ of the MTD was chosen. The development of a skin rash was found to correlate with clinical benefit and in the BR.21 erlotinib trial there was a strong correlation between the severity of the rash and survival time (hazard ratio [HR] HR 0.51 grade 1 and 0.34 for grade $\geq 2$ ). ${ }^{82}$ The gefitinib trial ISEL demonstrated the rate of rash to be $37 \%$ and $2 \%$ grade 3 and 4 respectively compared to the BR.21 trial where the rate of grade 3 and 4 rash was $76 \%$ and $9 \%$ respectively (see Table 3 ).

\section{Tolerability}

There are clear contraindications in the use of gefitinib and these include breastfeeding, as animal studies have found that levels of gefitinib and its metabolites are higher in milk than blood. ${ }^{34}$ There is also evidence of human fetal risk, but benefits from use in pregnancy may outweigh the risk, and therefore it is categorized as FDA pregnancy Category D. Gefitinib contains lactose and is not recommended in patients with rare hereditary problems of galactose intolerance, the Lapp lactose deficiency, or glucose-galactose malabsorption. The monitoring of toxicities includes monthly assessment of full blood count, urea and electrolytes and liver function tests. A mild rise in alanine aminotransferase is common; however, rises in bilirubin and progression to hepatitis are rare. Gefitinib is generally well tolerated, with the most frequently reported side effects being skin rash, diarrhea, nausea, vomiting and anorexia. The IDEAL studies demonstrated the tolerability of gefitinib at the $250 \mathrm{mg} /$ day dose and found the adverse events were dose related and increased in frequency at $500 \mathrm{mg} /$ day; they generally occurred early within the first month of treatment and appeared to be noncumulative. ${ }^{84}$

When compared to second line chemotherapy in the INTEREST trial ${ }^{59}$ significant adverse events with gefitinib compared to docetaxel included rash/acne (49.4\%), dry skin $(15.2 \%)$ and diarrhea (35\%), whereas the significant side effects of docetaxel compared to gefitinib were: hematological toxicity (neutropenia $73.7 \%$, anemia $11.7 \%$ ); alopecia (35.5\%); myalgia $(15.8 \%)$; pyrexia $(16.5 \%)$; fluid retention (15.7\%); constipation (16.9\%); neurotoxicity (23.9\%); nausea (26.2\%); and asthenic disorders (46.7\%). Serious adverse events leading to cessation of therapy were observed in $8 \%$ and $14 \%$ with gefitinib and docetaxel respectively, and adverse events leading to death were similar for both groups at $4 \%$.

The characteristic rash is commonly seen on the face, thorax and back. It is acneiform in nature. It is treatable although rarely resolves with continued administration of gefitinib. With a mild rash (ie, no infection/localized/no impact on activities of daily living), topical hydrocortisone cream or clindamycin gel can be used with continuation of EGFR inhibitor. With a moderate rash (ie, no infection/ generalized/minimal impact on activities of daily living), oral tetracyclines may be added to the topical preparations with the continuation of a EGFR inhibitor. With a severe rash (ie, severe symptoms, generalized, impact on activities of daily living and possible infection), then topical steroids, clindamycin gel and oral tetracyclines should be instigated with a dose reduction or consideration of interruption of the EGFR inhibitor. ${ }^{85,86}$ The association between the presence of skin toxicity and improved survival and overall response, has lead to the suggestion of dose escalation of the EGFR inhibitors until development of skin toxicity or diarrhea. This strategy has not been incorporated into standard clinical practice as there was clear evidence of tumor response in the EGFR trials independent of the degree of skin toxicity. Clinically, an increasing dose will lead to a higher incidence of CTC grade $\geq 3$ toxicity and thus leading to dose reductions and the interruption of treatment.

Interstitial lung disease (ILD) is a recognized, albeit rare, side effect of gefitinib and other anticancer therapies 
Table 3 Summary of major toxicites experienced in ISEL and BR.2 I

\begin{tabular}{|c|c|c|c|c|}
\hline \multirow[t]{2}{*}{ Adverse events } & \multicolumn{2}{|l|}{ ISEL } & \multicolumn{2}{|l|}{ BR.2I } \\
\hline & All grades (\%) & Grade $\geq 3(\%)$ & All grades (\%) & Grade $\geq 3(\%)$ \\
\hline Neutropenia & - & - & - & - \\
\hline Anemia & - & - & - & - \\
\hline Thrombocytopenia & - & - & - & - \\
\hline Diarrhea & 27 & 3 & 55 & 6 \\
\hline Nausea & 17 & 1 & 40 & 3 \\
\hline Vomiting & 14 & I & 25 & 3 \\
\hline Anorexia & 17 & 2 & 69 & 9 \\
\hline Stomatitis & 6 & - & 19 & $<1$ \\
\hline Rash & 37 & 2 & 76 & 9 \\
\hline Lung infection/pneumonia & 4 & 3 & 34 & 2 \\
\hline Pneumonitis & I & - & 3 & $<1$ \\
\hline Hepatotoxicity & $<5$ & 0 & 4 & 0 \\
\hline
\end{tabular}

in patients with lung cancer. Symptoms include the sudden onset of progressive dyspnea which may be associated with a cough or fever. Differential diagnoses include: pneumonia; radiation induced pneumonitis; and lymphangitic carcinomatosis; it is fatal in one third of cases. ${ }^{87}$ Treatment includes the withdrawal of the causative agent, oxygen, steroids and antibacterials. The INTEREST trial reported rates of $1.4 \%$ with gefitinib compared to $1.1 \%$ with docetaxel, whereas the ISEL trial reported an incidence of $1 \%$ with gefitinib. Associated factors predisposing to an increased incidence include: poor performance status; increasing age; prior existing lung disease or heart disease; and smoking history. ${ }^{89}$ Worldwide the incidence of ILD with gefitinib is $0.88 \%$ at $250 \mathrm{mg} / \mathrm{day},{ }^{88}$ and appears to be more common in Japanese patients (with an incidence of 1.9\%); the reasons for this discrepancy remain unclear. The mechanism of injury is unclear but EGFR is thought to play a role in normal repair, ${ }^{89}$ therefore the blockade of this receptor in a patient with pulmonary co-morbidities or propensity to injury can lead to ILD.

Despite potential toxicities, gefitinib has demonstrated acceptable tolerability in patients, and as an orally administered treatment, with fewer hematological side effects, and hospitalization rates are lower than with other common cytotoxic drugs used in NSCLC, ie, docetaxel..$^{90}$

\section{Which patient population will benefit from gefitinib?}

Extensive research has been undertaken in an attempt to identify a subgroup of patients who can be predicted to have an improved response with EGFR inhibitors. Sensitivity to EGFR inhibitors may be influenced by mutational analysis and high EGFR gene copy number. ${ }^{91-94}$ Dahabreh and colleagues demonstrated, in a meta analysis of over 4000 patients with NSCLC treated with TKIs, that EGFR mutations were sensitive and specific predictors of response to TKI, and to a lesser extent high EGFR gene copy number. ${ }^{92}$ Mixed results have been obtained when using EGFR protein expression as a predictor of response. ${ }^{95-97}$ KRAS mutations have been associated with an increased resistance to EGFR inhibitors ${ }^{96}$ as they may result in the activation of the oncogenic pathway Ras/Raf/Mek/ErK. ${ }^{98}$

\section{Pretreated NSCLC}

Hirsch and colleagues undertook a biomarker analysis on those patients in the ISEL trial. ${ }^{97}$ Analyses done included: EGFR protein expression assessed by immunohistochemistry; EGFR mutation assessed by DNA sequencing of exons 18 to 24; and polymerase chain reaction (PCR) to detect exon 21 L858R point mutation and exon 19 deletion; EGFR gene copy number assessed by florescent in situ hybridization (FISH); and KRAS mutation identified as for EGFR mutations. Of the 1692 patients, 460 (27.2\%) had tissue samples that were assessable. A little more than $30 \%$ had a high EGFR gene copy number and achieved better survival with gefitinib as compared to placebo $(P=0.045)$ than those with a low EGFR gene copy number. Over $69.6 \%$ had high EGFR protein expression and those patients achieved better survival with gefitinib than placebo $(P=0.049)$ than patients with a low EGFR protein expression. Just over $12.1 \%$ of patients were positive for EGFR mutations with the most frequent mutations being exon 19 deletions and exon 21 point mutations. Patients who were female, never smokers, Asian or adenocarcinoma were more likely to have EGFR mutations, and the objective tumor response to gefitinib was greater in this group than placebo $(37.5 \%$ versus $2.6 \%$ 
respectively). KRAS mutations were detected in $7.9 \%$ patients although the patient numbers were too small to draw meaningful conclusions regarding any response to treatment.

In a preplanned subgroup analysis of 174 patients from the INTEREST trial, there was no proof of a superior overall survival with gefitinib as compared with docetaxel in patients with a high EGFR gene copy number $(\mathrm{HR}=1.09)$. Clinical factors including being a never smoker, Asian, female, or adenocarcinoma, predicted a longer overall survival when compared to the study population, although this was irrespective of whether these patients received gefitinib or docetaxel.

The V-15-32 study found similar results to INTEREST with EGFR mutation positive patients having a better PFS on either gefitinib or docetaxel with no difference in OS between the two therapies.

\section{Chemonaïve NSCLC}

Rosell and colleagues ${ }^{28}$ screened 2105 patients in Spain from April 2005 to November 2008, and those patients with an EGFR mutation were eligible for erlotinib treatment. 350 EGFR mutations were identified (16.6\%), mutations were more frequent in women (69.7\%), never smokers (66.6\%) and adenocarcinomas $(80.9 \%)$. The common mutations were deletions in exon 19 $(62.2 \%)$ and mutation in L858R (37.8\%). The hazard ratios for progression free survival were 1.92 for exon $19(P=0.02)$ and 1.68 for L858R mutation $(P=0.02)$, suggesting that the screening of patients with lung cancer for EGFR mutations may allow more accurate tailoring of treatment.

The iTARGET study prospectively identified patients with EGFR mutations in a Western population. 98 patients were screened and 34 were identified with EGFR mutations. 31 patients chose to proceed with daily gefitinib and the overall response rate was $55 \%$ and median PFS and OS of 9.2 months and 17.5 months respectively. ${ }^{98}$

IPASS compared gefitinib with carboplatin-paclitaxel in a first line treatment in an Asian population and found EGFR mutations in 261 patients; with the common mutations being consistent with those identified in previous studies. PFS was significantly longer in those who received gefitinib and were EGFR mutation positive $(P<0.001)$, ORR with gefitinib was $71.2 \%$ versus $1.1 \%$ in the mutation positive subgroup as compared to the mutation negative subgroup. More importantly the use of gefitinib rather than chemotherapy in EGFR mutation negative patients conferred a treatment disadvantage, thus demonstrating the importance of tailoring the choice of treatment to EGFR status to ensure each patient receives the therapy they are predicted to have the greatest chance of response to. Overall survival data is not yet mature as follow-up in the major studies is ongoing.

Inoue and colleagues compared gefitinib with placebo in poor performance status patients $(\geq 3)$ with NSCLC and confirmed EGFR mutations. 30 patients were recruited and the overall response rate was $66 \%$ with PS improvement in $79 \%(P<0.00005)$. The median PFS was 6.5 months and OS 17.8 months indicating gefitinib can be used safely in poor PS patients and improve PFS and OS over what would be expected in this patient subset. ${ }^{99}$

More recently the WJTOG3405 trial, a randomized phase III trial, compared gefitinib with cisplatin and docetaxel as first line treatments in patients with activating EGFR mutations and PS 0-1. The number of patients recruited was 177 and the gefitinib group demonstrated a significantly prolonged median PFS compared to chemotherapy (9.2 months versus 6.3 months $P<0.0001$ ) thus demonstrating, in a population selected by mutational analysis, the use of gefitinib at first line leads to prolonged PFS. ${ }^{100}$ Similarly, gefitinib was compared with carboplatin and paclitaxel, in patients with EGFR mutations and demonstrated similar results with an ORR with gefitinib versus chemotherapy of $74 \%$ versus $29 \%$ $(P<0.001)$ and PFS prolonged with gefitinib $(10.4$ months versus 5.5 months, $P<0.001) .{ }^{101}$

The i-CAMP study recently reported, and demonstrated, a significantly prolonged median PFS in patients with EGFR mutations treated with gefitinib as a single agent. The results indicated that single agent gefitinib leads to a longer PFS when used at first line rather than chemotherapy (10.7 versus 6 months, $P<0.001$ ), but no significant difference was seen in median OS. Good PS and chemonaïve status were significantly associated with longer PFS. ${ }^{102}$

\section{Future directions}

There is now a plethora of data supporting the use of gefitinib in NSCLC. When to use it and in which patients is becoming more clearly defined. AstraZeneca have ongoing research into identifying mutations in the general population, and thus accurately targeting therapies to those patients with the highest likelihood of response. With the widespread use of erlotinib at second line, the place of gefitinib in the molecular algorithm needs to be defined. AstraZeneca are currently in negotiations with European Regulatory body EMEA regarding a further trial which will mirror IPASS, although in a Western population, this may provide the evidence needed to support the use of gefitinib as a first line agent in a selected population. Currently in the 
UK, the National Institute for Health and Clinical Excellence (NICE) has not recommended the use of gefitinib for second line use. AstraZeneca have informed NICE that it intends to focus its efforts on gefitinib in the first-line treatment of advanced NSCLC for patients with EGFRTK mutation positive tumors. ${ }^{103}$ Further data are needed regarding EGFR in combination with other therapies, either with other targeted agents or chemotherapeutic agents. The timing of chemotherapy and EGFR inhibitors may require review as preclinical studies suggest that gefitinib causes G1 arrest of EGFR-dependent tumors which could thus render cells less sensitive to cytotoxic agent. ${ }^{104}$

With increasing use of targeted therapies in NSCLC there is likely to be an increase in the issue of EGFR inhibitor resistance, and ways to overcome this resistance will need to be a focus of future research. Whether multi-targeted agents will reduce this problem is the source of ongoing clinical trials (ie, ZEPHYR), zactima plus best supportive care versus placebo and best supportive care.

\section{Conclusions}

NSCLC has previously had a very poor prognosis and few effective therapies, therefore the identification of new therapies should be welcomed. The future is likely to see therapies targeted not only to the tumor diagnosis but also to the patient's own tumor characteristics. EGFR testing will hopefully assist greatly with this, allowing us to tailor treatment to the individual at diagnosis and relapse. The results of recent selected population trials including I-CAMP and WJTOG3405 support this future.

We hope to see a future where patients are treated at first line, according to their EGFR-TK mutational status, allowing accurate tailoring of anticancer therapy to individuals, and ensuring the range of possible therapies, in this historically chemotherapy resistant tumor, is increased.

\section{Disclosures}

The authors confirm no conflicts of interest either commercial or financial relevant to this research.

\section{References}

1. Office for National Cancer Statistics, Cancer Statistics Registrations: registrations of cancer diagnosed in 2006, England. 2009.

2. Franceschi S, Bidoli E. The epidemiology of lung cancer. Ann Oncol. 1999,10:3-6.

3. Cancer reference information, American Cancer Society. 2009.

4. Maione P, Gridelle C, Troiani T, et al. Combining Targeted Therapies and drugs with multiple targets in the treatment of NSCLC. Oncologist. 2006;11:274-284.
5. Non-small-cell lung cancer Collaborative Group. Chemotherapy in non-small-cell lung cancer: a meta-analysis using updated data on individual patients from 52 randomized clinical trials. $B M J$. 1995;311:899-909.

6. Schiller JH, Ramalingam SS, et al. Duration of chemotherapy for metastatic non-small-cell lung cancer: more may be better after all. J Clin Oncol. 2009;27:3265-3267.

7. Fujino S, Enokibori T, Tezuka N, et al. A comparison of epidermal growth factor receptor levels and other prognostic parameters in non-small-cell lung cancer. Eur J Cancer. 1996;32A:2070-2074.

8. Veale D, Kerr N, Gibson GJ, et al. The relationship of quantitative epidermal growth factor receptor expression in non-small-cell lung cancer to long term survival. Br J Cancer. 1993;68:162-165.

9. Blackhall F, Ranson M, Thatcher N. Where next for gefitinib in patients with lung cancer? Lancet. 2006;7:499-507.

10. Gazdar AF. Activating and resistance mutations of EGFR in non-smallcell lung cancer: role in clinical response to EGFR tyrosine kinase inhibitors. Oncogene. 2009;28:24-31.

11. Hirsch FR, Franklin WA, McCoy J. Predicting clinical benefit from EGFR TKIs: not all EGFR mutations are equal. $J$ Clin Oncol. 2006;24:382.

12. Jackman DM, Yeap BY, Sequist LV, et al. Exon 19 deletion mutations of epidermal growth factor receptor are associated with prolonged survival in non-small-cell lung cancer patients treated with gefitinib or erlotinib. Clin Cancer Res. 2006;12:3908-3914.

13. Yang $\mathrm{CH}$, Yu CJ, Shih JY, et al. Specific EGFR mutations predict treatment outcome of stage IIIB/IV patients with chemotherapy-naive non-small-cell lung cancer receiving first line gefitinib therapy. $J$ Clin Oncol. 2008;26:2745-2753.

14. Shigematsu H, Gadzar AF. Somatic mutations of epidermal growth factor receptor-signaling pathway in lung cancers. Int $J$ Cancer. 2006;118:257-262.

15. Pao W, Wang TY, Reily GJ, et al. KRAS mutations and primary resistance of lung adenocarcinomas to gefitinib or erlotinib. PLoS Med. 2005;2:e17.

16. Massarelli E, Varella-Garecia M, Tang X, et al. KRAS mutation is an important predictor of resistance to therapy with Epidermal Growth Factor Receptor Tyrosine Kinase Inhibitors in non-small-cell lung cancer. Clin Cancer Res. 2007;13:2890-2896.

17. Bianco R, Troiani T, Tortora G, et al. Intrinsic and acquired resistance to EGFR inhibitors in human cancer therapy. Endocr Relat Cancer. 2005;12:159-171.

18. Engleman JA, Janne PA. Mechanisms of acquired resistance to epidermal growth factor receptor tyrosine kinase inhibitors in non-small cell lung cancer. Clin Cancer Res. 2008;14:2895-2899.

19. Kobayashi S, Boggon TJ, Dayaram T, et al. EGFR mutation and resistance of non-small-cell lung cancer to gefitinib. $N$ Engl $J$ Med. 2005;352:786-792.

20. Maheswaran S, Sequist L, Nagrath S, et al. Detection of mutations in EGFR circulating lung cancer cells. N Engl J Med. 2008;359:366-377.

21. Zhou W, Ercan D, Chen D, et al. Novel mutant-selective EGFR kinase inhibitors against EGFR T790M. Nature. 2009;462:1070-1074.

22. Toyooka S, Matsuo K, Shigematsu H, et al. The impact of sex and smoking status on the mutational spectrum of epidermal growth factor receptor gene in non-small-cell lung cancer. Clin Cancer Res. 2007; 13:5763-5768.

23. Haneda H, Saski H, Lindeman N, et al. A correlation between EGFR gene mutation status and bronchioalveolar carcinoma features in Japanese patients with adenocarcinoma. Jap J Clin Oncol. 2006;36:69-75.

24. Sugio K, Uramoto H, Ono K, et al. Mutations within the tyrosine kinase domain of EGFR gene specifically occur in lung adenocarcinoma patients with a low exposure of tobacco smoking. Br J Cancer. 2006; 94:896-903.

25. Mounawar M, Mukeria A, Le Calvez F, et al. Patterns of EGFR, HER2, TP53, and KRAS mutations of p14 ${ }^{\text {afr }}$ expression in non-smallcell lung cancers in relation to smoking history. Cancer Res. 2007; 67:5667-5672. 
26. Toyooka S, Tokumo M, Shigematsu H, et al. Mutational and epigenetic evidence for independent pathways for lung adenocarcinomas arising in smokers and never smokers. Cancer Res. 2006; 66:1371.

27. Sonobe M, Manabe T, Wada H, et al. Mutations in the epidermal growth factor receptor gene are linked to smoking-independent, lung adenocarcinoma. Br J Cancer. 2005;93:355-363.

28. Rosell R, Moran T, Queralt C, et al. Screening for epidermal growth factor receptor mutations in lung cancer. $N$ Engl J Med. 2009; 361:958-967.

29. Wu JY, Yu CJ, Yang CH, et al. First or second line therapy with gefitinib produces equal survival in non-small cell lung cancer. Am J Resp Crit Care Med. 2008;178:847-853.

30. Asahina H, Yamazaki K, Kinoshita I, et al. A phase II trial of gefitinib as first line therapy for advanced non-small-cell lung cancer with epidermal growth factor receptor mutations. Br J Cancer. 2006;95: 998-1004.

31. Inoue A, Suzuki T, Fukuhara T, et al. Prospective Phase II study of gefitinib for chemotherapy-naive patients with advanced non-small-cell lung cancer with epidermal growth factor receptor gene mutations. J Clin Oncol. 2006;24:3340-3346.

32. Tamura K, Okamoto I, Kashii T, et al. Multicentre prospective phase II trial of gefitinib for advanced non-small-cell lung cancer with epidermal growth factor receptor mutations: results of the West Japan Thoracic Oncology Group trial. Br J Cancer. 2008;98: 907-914.

33. Sequist LV, Martins R, Spigel DR, et al. First line gefitinib in patients with advanced non-small-cell lung cancer harboring somatic EGFR mutations. J Clin Oncol. 2008;26:2442-2449.

34. Gefitinib. British Columbia Cancer Agency Drug Manual. 2004.

35. Kim ES, Mauer AM, William WN Jr, et al. A phase II of cetuximab, an epidermal growth factor receptor (EGFR) blocking antibody, in combination with docetaxel in chemotherapy resistant/refractory patients with advanced non-small-cell lung cancer. Cancer. 2009;115 1713-1722.

36. Hanna N, Lilenbaum R, Ansari R, et al. A phase II trial of cetuximab in patients with previously treated non-small-cell lung cancer. $J$ Clin Oncol. 2006;24:5253-5258.

37. Thienelt CD, Bunn PA Jr, Hanna N, et al. Multicenter phase I/II study of cetuximab in combination with paclitaxel and carboplatin in untreated patients with stage IV non-small-cell lung cancer. $J$ Clin Oncol. 2005;23:8786-8793.

38. Robert F, Blumenschein K, Herbst RS, et al. Phase Ib/IIa study of cetuximab with gemcitabine plus carboplatin in patients with chemotherapy-naive advanced non-small-cell lung cancer. J Clin Oncol. 2005; 23:9089-9096.

39. Gatzemeier U, Rossel R, Ramlau R, et al. Cetuximab in combination with cisplatin/vinorelbine versus cisplatin/vinorelbine alone in the first line treatment $\mathrm{f}$ patients with epidermal growth factor receptor (EGFR) positive advanced non-small-cell lung cancer (NSCLC). Am Soc Clin Oncol. 2003;22:624.

40. Pirker R, Pereira J, Szczesna A, et al. Cetuximab plus chemotherapy in patients with advanced non-small-cell lung cancer(FLEX): an open label randomized phase III trial. Lancet. 2009;373:1525-1531.

41. Shepherd FA, Rodrigues PJ, Ciuleanu T, et al. Erlotinib in previously treated non-small-cell lung cancer. $N$ Engl J Med. 2005; 353:123-132.

42. Herbst RS, Prager D, Hermann R, et al. TRIBUTE: a phase III trial of erlotinib hydrochloride (OSI-774) combined with carboplatin and paclitaxel chemotherapy in advanced non-small-cell lung cancer. J Clin Oncol. 2005;23:5892-5899.

43. Shepherd FA, Rodrigues PJ, Ciuleanu T, et al. Erlotinib in previously treated non-small-cell lung cancer. $N$ Engl J Med. 2005;353:123-132.

44. Cappuzzo F, Coudert BPT, Wierzbicki R, et al. Efficacy and safety of erlotinib as first line maintenance in NSCLC following non-progression with chemotherapy: results from the phase III SATURN study. J Thor Oncol. 2009;4:Abstr A21.
45. Herbst R, et al. Vandetanib plus docetaxel versus docetaxel as second line treatment for patients with advanced non-small-cell lung cancer: a randomized, double blind, phase III trial (ZODIAC). J Clin Oncol. 2009;27:Abstr 31495.

46. De Boer R, Humblet Y, Wolf J, et al. An open label study of vandetanib with pemetrexed in patients with previously treated non-small-cell lung cancer. Ann Oncol. 2009;20:486-491.

47. Natale R, et al. Vandetanib versus erlotinib in patients with advanced non-small-cell lung cancer after failure of at least one prior cytotoxic chemotherapy: a randomized double blind phase III trial (ZEST). J Clin Oncol. 2009;27:Abstr 31610.

48. Zactima - Tyrosine Kinase Inhibitor for treatment of Lung Cancer. 2009. www.drugdevelopment.technology.com.

49. Natale RB, Bodkin D, Govindan R, et al. Vandetanib versus gefitinib in patients with advanced non-small-cell lung cancer; results from a two part, double blind, randomized phase II study. J Clin Oncol. 2009;27:2523-2529.

50. Lorusso PM. Phase I studies of ZD1839 in patients with common solid tumors. Semin Oncol. 2003;30:21-29.

51. Baselga J, Rischin D, Ranson M, et al. Phase I safety, pharmacokinetic, and pharmacodynamic trial of ZD1839, a selective oral epidermal growth factor receptor tyrosine kinase inhibitor, in patients with five selected solid tumor types. J Clin Oncol. 2002;20:4292-4302.

52. Herbst RS, Maddox AM, Rothenberg ML, et al. Selective oral epidermal growth factor receptor tyrosine kinase inhibitor ZD1839 is generally well tolerated and has activity in non-small-cell lung cancer and other solid tumors: results of a phase I trial. J Clin Oncol. 2002;20:3815-3825

53. Nakagawa K, Tamura T, Negoro S, et al. Phase I pharmacokinetic trial of the selective oral epidermal growth factor receptor tyrosine kinase inhibitor Gefitinib in Japanese patients with solid tumors. Ann Oncol. 2003;14:922-930.

54. Ranson M, Hammond LA, Ferry D, et al. ZD1839, a selective oral epidermal growth factor receptor tyrosine kinase inhibitor is well tolerated and active in patients with solid tumors: results of a phase I trial. J Clin Oncol. 2002;20:2240-2250.

55. Fukuoka M, Yano S, Giaccone G, et al. Multi-institutionalized randomized phase II trial of gefitinib for previously treated patients with advanced non-small-cell lung cancer. J Clin Oncol. 2003; 21:2237-2246.

56. Kris MG, Natale RB, Herbst RS, et al. Efficacy of gefitinib, an inhibitor of the epidermal growth factor receptor tyrosine kinase, in symptomatic patients with non-small-cell lung cancer. A randomized trial. JAMA. 2003;290:2149-2158

57. Crufer T, Vrdoljak E, Gaafar R, et al. Phase II open label randomized study (SIGN) of single agent gefitinib (IRESSA) or docetaxel as second line therapy in patients with advanced (stage IIIb or IV) non-small-cell lung cancer. Anticancer Drugs. 2006;17:401-409.

58. Thatcher N, Chang A, Parikh P, et al. Gefitinib plus best supportive care in previously treated patients with refractory advanced non-small-cell lung cancer: results from a randomized, placebo-controlled, multicentre study (Iressa Survival Evaluation in Lung Cancer). Lancet. 2005; 366:1527-1537.

59. Kim ES, Hirsch V, Mok T, et al. Gefitinib versus docetaxel in previously treated non-small-cell lung cancer: a randomized phase II trial (INTEREST). Lancet. 2008;372:1809-1818.

60. Maruyama R, Nishiwaki Y, Tamura T, et al. Phase III study, V-15-32, of gefitinib versus docetaxel in previously treated Japanese patients with non-small-cell lung cancer. J Clin Oncol. 2008;26: 4244-4252.

61. Lee D, Kim S, Park K, et al. A randomized open label study of gefitinib versus docetaxel in patients with advanced/metastatic non-small-cell lung cancer who have previously received platinum based chemotherapy. J Clin Oncol. 2008;26(Suppl).

62. Reck M, Buchholz E, Romer KS, et al. Gefitinib monotherapy in chemotherapy-naïve patients with inoperable stage III/IV non-small-cell lung cancer. Clini Lung Cancer. 2006;7:406-411. 
63. Speil DR, Hainsworth JD, Burkett ER, et al. Single-agent gefitinib in patients with untreated advanced non-small-cell lung cancer and poor performance status: a Minnie Pearl Cancer. Research Network Phase II trial. Clin Lung Cancer. 2005;7:127-132.

64. Agiris A, Mittal N. Gefitinib as first line, compassionate use therapy in patients with advanced non-small-cell lung cancer. Lung Cancer. 2004; 43:317-322.

65. D'Addario G, Rauch D, Stupp R, et al. Multicentre phase II trial of Gefitinib as first line therapy followed by chemotherapy in advanced non-small-cell lung cancer: SAKK protocol 19/03. Ann Oncol. 2008; 19:739-745.

66. Niho S, Kubota K, Goto K, et al. First line single agent treatment with gefitinib in patients with advanced non-small-cell lung cancer: a phase II study. J Clin Oncol. 2006;24:64-69.

67. Suzuki R, Hasegawa Y, Baba K, et al. A phase II study of single agent gefitinib as first line therapy in patients with stage IV non-small-cell lung cancer. Br J Cancer. 2006;94:1599-1603.

68. Crino L, Cappuzzo F, Zatloukal P, et al. Gefitinib versus vinorelbine in chemotherapy-naieve elderly patients with advanced non-small-cell lung cancer (INVITE): a randomized phase II study. J Clin Oncol. 2008;26:4253-4260.

69. Goss G, Ferry D, Wierzbicki R, et al. Randomized phase II study of gefitinib compared with placebo in chemotherapy naieve patients with advanced NSCLC and poor performance status. J Clin Oncol. 2009;27:2253-2260.

70. Giaccone G, Herbst RS, Manegold C, et al. Gefitinib in combinations with gemcitabine and cisplatin in advanced non-small-cell lung cancer: a phase III trial-INTACT 1. J Clin Oncol. 22:777-784.

71. Herbst RS, Giaccone G, Schiller JH, et al. Gefitinib in combination with paclitaxel and carboplatin in advanced non-small-cell lung cancer: A phase III trial- INTACT 2. J Clin Oncol. 2004;22: 785-794.

72. MokTS, WuYL, Thongprasert S, et al. Gefitinib or carboplatin-paclitaxel in pulmonary adenocarcinoma. $N$ Engl J Med. 2009;361:947-957.

73. Mencoboni M, Bergaglio M, Serra M, et al. Maintenance therapy with gefitinib after first line chemotherapy in patients affected by advanced non-small-cell lung cancer. Anticancer Rese. 2007;27:4 425-4429.

74. Wang MZ, Zhong W, Zhang L, et al. Efficacy and safety of gefitinib in maintenance therapy for patients with advanced non-small-cell lung cancer. Jap J Clin Oncol. 2008;30:221-224.

75. Hida T, Okamoto I, Kashii T, et al. Randomized phase III study of platinum-doublet chemotherapy followed by gefitinib versus continued platinum-doublet chemotherapy in patients (pts) with advanced non-small cell lung cancer (NSCLC): Results of West Japan Thoracic Oncology Group trial (WJTOG). J Clin Oncol. 2008;26: Abstr LBA8012.

76. Kelly K, Chansky K, Gaspar LE, et al. Phase III trial of maintenance gefitinib or placebo after concurrent chemoradiotherapy and docetaxel consolidation in inoperable stage III non-small-cell lung cancer: SWOG S0023. J Clin Oncol. 2008;26:2450-2456.

77. Adjei AA, Molina JR, Mandrekar SJ, et al. Phase I trial of sorafenib in combination with gefitinib in patients with refractory or recurrent non-small-cell lung cancer. Clin Cancer Ther. 2007;13:2684.

78. Cruijsen HV, Voest EE, Van Herpen CML, et al. Phase I clinical evaluation of AZD2171 in combination with gefitinib, in patients with advanced tumors. J Clin Oncol. 2006;24: Abstr 3017.

79. Milton DT, Reily GJ, Azzoli CG, et al. Phase I trial of everolimus and gefitinib in patients with advanced non-small-cell lung cancer. Cancer. 2007;110:599-605.

80. Kris MG, Riely GJ, Azzoli CG, et al. Combined inhibition of mTOR and EGFR with evorilimus and gefitinib in patients with non-small-cell lung cancer who have smoked cigarettes: A phase II trial. J Clin Oncol. 2007;25:7575.

81. Perez-Soler R, Chachoua A, Hammond LA, et al. Determinants of tumor response and survival with erlotinib in patients with non-small-cell lung cancer. J Clin Oncol. 2004;22:3238-3247.
82. Shepherd FA, Rodrigues PJ, Ciuleanu T, et al. Erlotinib in previously treated non-small-cell lung cancer. $N$ Engl J Med. 2005; 353:123-132.

83. Haura E, Sommers E, Becker D, et al. Pilot phase II study of preoperative gefitinib in early stage non-small-cell lung cancer with assessment of intratumor gefitinib levels and tumor target modulation. $J$ Clin Oncol. 2007;25: Abstr 7603.

84. Fukuoka M, Kris M, Giaccone G, et al. Phase II trials of gefitinib: rapid and durable objective responses in patients with advanced non-smallcell lung cancer (IDEAL I and IDEAL II). Lung Cancer. 2003;41: S247-S248.

85. Shah NT, Kris MG, Pao W, et al. Practical management of patients with non-small-cell lung cancer treated with gefitinib. J Clin Oncol. 2005;23:156-174.

86. Lynch TJ, Kim ES, Eaby B, et al. Epidermal growth factor receptor inhibitor-associated cutaneous toxicities: an evolving paradigm in clinical management.Oncologist. 2007;12:610-621.

87. Danson S, Blackhall F, Hulse P, et al. Interstitial lung disease in lung cancer; separating disease progression from treatment side effects. Drug Safety. 2005;28:103-113.

88. Jiang H. Overview of gefitinib in non-small-cell lung cancer: An Asian perspective. Jap J Clin Oncol. 2009;39:137-150.

89. Madtes DK, Busby HK, Strandjord TP, et al. Expression of transforming growth factor alpha and epidermal growth factor receptor is increased following bleomycin-induced lung injury in rats. Am J Resp Cell Molec Biol. 1994;11:540-541.

90. Ranson M, Wardell S, et al. Gefitinib, a novel, orally administered agent for the treatment of cancer. J Clin Pharm Ther. 2004;29:95-103.

91. Cappuzzo F, Hirsh FR, Rossi E, et al. Epidermal growth factor receptor gene and protein and gefitinib sensitivity in non-small-cell lung cancer. J Nat Cancer Inst. 2005;97:643-655.

92. Dahabreh IJ, Linardou H, Sannis F, et al. Somatic EGFR mutation and gene copy gain as predictive biomarkers for response to tyrosine kinase inhibitors in non-small cell lug cancer. Clin Cancer Res. 2009;16:291-303.

93. Tsao MS, Sakurada A, Cutz JC, et al. Erlotinib in lung cancer: molecular and clinical predictors of outcome. $N$ Engl J Med. 2005; 353:133-144.

94. Bailey LR, Kris M, Wolf M, et al. Tumor EGFR membrane staining is not clinically relevant for predicting response in patients receiving gefitinib monotherapy for pretreated advanced non-small-cell lung cancer: IDEAL I and 2. Presented at the American Association Cancer Research, Washington, DC, 2003 July 11-14. Poster LB-212.

95. Hirsch FR, McCoy J, Cappuzzo F, et al. FISH and immunohistochemistry can be used to select NSCLC patients who will benefit from gefitinib treatment. Lung Cancer. 2005:49:S38.

96. Pao W, Wang TY, Reily GJ, et al. KRAS mutations and primary resistance of lung adenocarcinomas to gefitinib or erlotinib. PloS Med. 2005;2:e17

97. Hirsch FR, Varella-Garcia M, Bunn P, et al. Molecular predictors of outcome with gefitinib in a phase III placebo-controlled study in advanced non-small-cell lung cancer. J Clin Oncol. 2006;24:5034-5042.

98. Sequist LV, Martins RG, Spigel D, et al. iTARGET: A phase II trial to assess the response to gefitinib in epidermal growth factor receptor (EGFR)-mutated non-small cell lung cancer (NSCLC) tumors. J Clin Oncol. 2007;25;7504.

99. Inoue A, Kobayashi K, Usui K, et al. First line gefitinib for patients with advanced non-small-cell lung cancer harboring epidermal growth factor receptor mutations without indication for chemotherapy. J Clin Oncol. 2009;27:1394-1400.

100. Mitsudomi T, Morita S, Yatabe Y, et al. Gefitinib versus cisplatin plus docetaxel in patients with non-small-cell lung cancer harboring mutations of epidermal growth factor receptor (WJTOG3405): an open label, randomized phase 3 trial. Lancet Oncol. 2009;11: $121-128$. 
101. Kobayashi K, Inoue A, Maemondo M, et al. First line gefitinib versus first line chemotherapy by carboplatin plus paclitaxel in non-smallcell lung cancer patients with EGFR mutations; A phase III study by North East Japan Gefitinib Study Group. J Clin Oncol. 2009;27:15S Abstr 8016

102. Morita S, Okamoto I, Kobayashi K, et al. Combined survival analysis of prospective clinical trials of gefitinib for non-small cell lung cancer with EGFR mutations. Clin Cancer Res. 2009;15: 4493-4498.
103. NICE technology appraisal 175 . Gefitinib for the second-line treatment of locally advanced or metastatic non-small-cell lung cancer. National Institute for Health and Clinical Excellence 2009 July.

104. Wakeling RS, Guy SP, Woodburn JR, et al. ZD1839 (Iressa): an orally active inhibitor of epidermal growth factor signaling with potential for cancer therapy. Cancer Res. 2002;62:5749-5754.

105. Herbst RS. ZDI839: targeting the epidermal growth factor receptor in cancer therapy. Expert Opin Investig Drugs. 2002;11:837-849.

\section{Publish your work in this journal}

Lung Cancer: Targets and Therapy is an international, peer-reviewed, open access journal focusing on lung cancer research, identification of therapeutic targets and the optimal use of preventative and integrated treatment interventions to achieve improved outcomes, enhanced survival and quality of life for the cancer patient. Specific topics covered in the journal include:

\section{Dovepress}

Epidemiology, detection and screening; Cellular research and biomarkers; Identification of biotargets and agents with novel mechanisms of action; Optimal clinical use of existing anticancer agents, including combination therapies; Radiation and surgery; Palliative care; Patient adherence, quality of life, satisfaction; Health economic evaluations.

Submit your manuscript here: http://www.dovepress.com/lung-cancer-targets--therapy-journal 